\title{
The molecular basis of nephrogenesis and congenital kidney disease
}

To the paediatrician, the kidney means disorders such as polycystic kidney disease, Wilms' tumour, congenital malformations, and nephrotic syndrome. To the developmental biologist, on the other hand, the kidney is important as a developmental model, partly because of the richness of its organisation and partly because, unusually for a mammalian tissue, much of its morphogenesis will take place in vitro. In the past, paediatric nephrologists and developmental biologists have not had much to say to one another, but, as kidney disorders with a genetic component are helping to illuminate the molecular basis of nephrogenesis and as it is becoming clear how the study of normal development can explain congenital kidney disease, their interests are converging and they have the techniques of molecular genetics to thank for this.

Such an approach to the study of nephrogenesis is relatively recent, but three lines of work are already under way. These are the searching of cDNA libraries coupled with in situ hybridisation to identity, characterise, and localise molecules expressed during normal and abnormal nephrogenesis, experimentation on cultured kidneys to investigate the role of these molecules, and the manufacture of transgenic mice with defective expression to show how development proceeds in their absence. Although there is a great deal more to come, enough is now known to illuminate something of the relationship between the molecular basis of normal development and the origins of congenital kidney disorders.

\section{Normal development}

Metanephric development in mammals begins soon after the hind limbs start to form when a small epithelial bud off the Wolffian duct invades a domain of dense metanephric mesenchyme (the metanephric blastoma). A reciprocal induction then takes place between the two and the bud extends and bifurcates to form the ureter and the collecting ducts, while the mesenchyme, under the influence of the nerves associated with the bud, differentiates into nephrons. ${ }^{1-3}$ This is a prolonged process with the outer part of the mesenchyme initially remaining as stem cells, while the inner cells rapidly associate into small aggregates. Each of these then epithelialises and undergoes the complex elongations and convolutions that lead to the formation of a nephron, with the one end fusing to a duct and the other interacting with capillaries and forming the renal capsule. ${ }^{4}$ Meanwhile, as these ducts extend, more of the peripheral stem cells enter the nephron pathway and then more, so that, in humans, some six tiers of nephrons form. As to development in vitro, an uninduced mouse rudiment will form a complex ducting system having perhaps 35 nephrons with glomeruli ${ }^{5}$ (albeit incomplete).

Some effort is being put into identifying genes that have a direct role in kidney function and how diseases like Alport's can arise if molecules such as collagen IV are aberrant. ${ }^{6}$ The main line of contemporary research, however, is in elucidating the molecular controls underpinning kidney development and, here, it is known that many of the transcription factors. $^{78}$ growth factors, ${ }^{9}$ and oncogenes ${ }^{10}$ involved in controlling gene expression throughout the embryo are expressed during nephrogenesis. ${ }^{11}$ In most cases, the functions of these molecules remains obscure, but experiments in which kidney rudiments are cultured in the presence of antisense oligonucleotides that block the transciption of the corresponding mRNA $^{12}$ may clarify their roles.

\section{Kidney disorders}

CONGENITAL MALFORMATIONS

Nephrogenesis is complicated, and it is one of the unstated marvels of development that the mature kidney is almost always normal. Nevertheless, things can easily go wrong that result in congenital malformations. ${ }^{13}$ If, for example, growth is slow or the regulation of stem cells goes awry, a small or hypoplastic kidney will result. If the two ureteric buds become so close that their respective mesenchymes interact (and they are only about $1-200 \mu \mathrm{m}$ apart when they first form in the mouse embryo), the resulting fusion will give rise to horseshoe kidneys. Such congenital disorders may be of medical concern, but experimental research will only be worth doing in cases where this is a clear heritable disorder or if there is a good animal model with which to work.

\section{WILMS' TUMOUR}

For these reasons, attention is now being focused on those diseases accessible to such analysis and the paradigm here is Wilm's tumour, a nephroblastoma where the control of stem cell differentiation is lost and whose aetiology involves a strong genetic component. ${ }^{14}$ Detailed analysis has now shown that the disease sometimes involves a molecule known as WT1 with at least two more being expected, one of which is associated with the Beckwith-Wiedmann syndrome and is at the $11 \mathrm{p} 15.5$ locus $^{15}$ where it shows strong evidence of imprinting together with tight linking to the IGF-2 site. ${ }^{14}$ WT1 is sited on the short arm of chromosome 11 at the $11 \mathrm{p} 13$ locus, is expressed in four alternative splice forms and its absence or mutation can lead to uncontrolled stem cell proliferation. Its genetics is, however, complex. In Wilms' tumour and the Wilms', Aniridia, Genital abnormalities, and mental Retardation (WAGR) syndrome, the WT1 locus is recessive and thus acts as a tumour suppressor, ${ }^{16}{ }^{17}$ in the Drash syndrome which is characterised by Wilms' tumour, pseudohermaphroditism, and renal failure the mutation is however dominant. ${ }^{18}$ Although we cannot yet explain this difference, these diseases do point to WT1 having an important role in the development of the urinogenital system.

The WT1 gene encodes a large protein with four zinc fingers that seem to bind to several DNA sequences controlling the expression of molecules likely to be involved in nephrogenesis. ${ }^{19}$ In the developing kidney WT1 is expressed in the uninduced stem cells, the early nephrons, and the glomeruli. Elsewhere it is present, inter alia, in the gonads, in several sites at which mesenchyme is making the transition to epithelium ${ }^{20}$ and in Wilms' tumour. ${ }^{21}$ To summarise our current view, it seems that WT1 is a transcription factor present in large amounts in induced metanephric mesenchyme and whose zinc finger site binds to several activation sites, so stimulating the cascade of the events that allows nephrogenesis to take place. In this context, it is not surprising that mutations in WT1 lead to aberrant induction and hence to cancer.

POLYCYSTIC KIDNEY DISEASES (PKD)

Perhaps the most important developmental disorder of kidneys, however, is the formation of cysts in the collecting ducts. Of the various types known, the most interesting academically is multicystic dysplasia: here, cysts appear during embryogenesis while nephrons fail to form due to a 
breakdown in induction. ${ }^{422}{ }^{23} \mathrm{We}$ do not yet have an exact animal analogue for this disease, but the C57BL/6J-cpk mouse is a good model for autosomal recessive PKD in which cysts also develop during embryongenesis. In this mouse, SGP-2, a cell-surface glycoprotein involved in epithelial development, is up-regulated in the cysts ${ }^{2+}$ and its presence there suggests that cyst formation arises from incomplete duct differentiation. This view is strengthened by the facts that $c-m y c$ and other oncogenes, normally present only during nephrogenesis, are also expressed in the kidneys of this mouse. ${ }^{25}$

The other inherited form of PKD is an autosomal dominant disease (ADPKD) which is characterised by the slow development of cysts. There is now a mouse that develops cysts over a relatively long period ${ }^{26}$ and hence is a model for this disease; the lesion here has, however, yet to be elucidated. Some intriguing evidence that the two forms of PKD may in some way be related is now being provided by a transgenic mouse which constitutively produces $c$-myc and develops ADPKD, ${ }^{27}$ although the dominant effect probably derives from the nature of the extra control genes in the transgenic mouse.

\section{The future}

Because of the importance of WT1 in both normal and abnormal development, substantial effort is being devoted to working out its function. This involves looking for DNA sites to which WT1 can bind, culturing kidneys in the presence of antisense oligonucleotides to WT1, trying to elucidate the roles of the various splice forms, and making transgenic mice in which WT1 expression is suppressed. Together, these approaches should tell us a great deal about both normal nephrogenesis and the initiation of kidney and perhaps other cancers

The use of trangenic mice to investigate Wilms' tumour is, it should be said, part of a major biomedical trend that is reflected in other areas of kidney research and, in addition to those already mentioned, such mice are being used to study renin production ${ }^{28}$ and nephrotic syndrome. ${ }^{29}$ These are thus exciting times for kidney research and, such is the rate of progress in this field, it should not be too long before we know a lot more about the molecular basis of congenital and other kidney diseases.

The author thanks the National Kidney Research fund for their support.

JONATHAN BARD

MRC Human Genetics Unit, Western General Hospital, Edinburgh EH4 $2 \mathrm{XU}$
1 Saxen L. Organogenesis of the kidney. Cambridge: Cambridge University Press, 1987

2 Sariola H, Aufderheide E, Bernhard H, Henke-Fahle S, Dippold W Ekblom $P$. Antibodies to cell surface ganglioside $G_{1 D^{3}}$ perturb inductive epitheliamesenchymal interactions. Cell 1988;54:235-45.

3 Sariola H, Holm K, Henke-Fahle H. Early innervation of the metanephric kidney. Development 1988;104:589-99.

4 Potter EL. Normal and abnormal development of the kidney. Chicago: Year Book Medical Publishers, 1972.

5 Bard JBL, Ross ASA. LIF the ES-cell inhibition factor reversibly blocks nephrogenesis in cultured mouse kidney rudiments. Development 1991;113: 193-8.

6 Tryggvason K. Cloning of Alport syndrome gene Ann Med 1991;23:237-9.

7 Mitchell PJ, Timmons PM, Hebert JM, Rigby PW, Tiian P. Transcripition factor AP-2 is expressed in neural chest cell lineages during mouse develop-

8 Kress C, Vogels R, de Craaff W, et al. Hox 2.3 upstream sequences mediate lacZ expression in intermediate mesoderm derivatives of transgenic mice. Development 1990;109:775-86.

9 Rogers SA, Ryan G, Hammerman MR. Insulin-like growth factors I and II are produced in the metanephros and required for growth and development in vitro. F Cell Biol 1991;113:1447-53.

10 Mugrauer G, Ekblom $P$. Contrasting expression patterns of the myc family of proto-oncogenes in the developing and adult mouse kidney. 7 Cell Biol 1991;112:13-25.

11 Bard JBL, Woolf AS. Nephrogenesis and the development of kidney disease. Nephrol Dial Transplant 1992 (in press).

12 Sariola H, Saarma M, Sainio K, et al. Dependence of kidney morphogenesis on the expression of nerve growth factor receptor. Science 1991;254:571-3.

13 Willis RA. The borderland of embryology and pathology. London: Butterworth, 1958 .

14 van Heyningen V, Hastie ND. Wilms' tumour: reconciling genetics and biology. Trends Genet 1992;8:16-21.

15 Koufos A, Grundy P, Morgan K, et al. Familial Wiedemann-Beckwith syndrome and a second Wilms' tumor locus both map to $11 \mathrm{pl5} .5$. Am 7 Hum Genet 1989;44:711-9.

16 Call KM, Glaser T, Ito CY, et al. Isolation and characterization of a zincfinger polypeptide gene at the human chromosome 11 Wilms' tumor locus. Cell 1990;60:509.

17 Gessler M, Poustka A, Cavenee W, Neve RL, Orkin SH, Bruns GAP. Homozygous deletion in Wilms' tumours of a zinc-finger gene identified by chromosome jumping. Nature 1990;343:774.

18 Pelletier J, Bruening W, Kashtan CE, et al. Germline mutations in the Wilms' tumor suppressor gene are associated with abnormal urinogenital development in the Denis-Drash syndrome. Cell 1991;67:437-47.

19 Madden SL, Cook DM, Morris JF, Gashler A, Sukhatme VP, Rauschler JR. Transcriptional repression mediated by the WTI Wilms' tumour gene product. Science 1991;253:1550-3.

20 Pritchard-Jones K, Fleming S, Davidson D, et al. The candidate Wilms' tumour gene is involved in genitourinary development. Nature 1990;346: 194.

21 Pritchard-Jones K, Fleming S. Gene types expressing the Wilms' tumour gene (WT1) in Wilms' tumours: implications for tumour histogenesis. Oncogene 1991;6:2211-20.

22 Crawford $M$ d'A. The genetics of renal tract disorders. Oxford: Oxford University Press, 1988.

23 Maizels M, Simpson SB. Primitive ducts of renal dysplasia induced by culturing urethral buds denuded by condensed renal mesenchyme. Science 1983; 219:509-10.

24 Harding MA, Chadwick LJ, Gattone VH, Calvet JP. The SGP-2 gene is developmentally regulated in mouse kidney and abnormally expressed in collecting duct cysts in polycystic kidney disease. Dev Biol 1991;146: 483-90.

25 Cowley BD, Chadwick LJ, Grantham JJ, Calvet JP. Elevated proto-oncogene expression in polycystic kidneys of the C57/6 J (cpk) mouse. Fournal of the American Society of Nephrology 1991:8:1048-53.

26 Takahashi H, Calvet JP, Dittemoore-Hoover D, Yashida K, Grantham JJ, Gattone VH. A hereditary model of slowly progressive polycystic kidney disease in the mouse. Foumal of the American Society of Nephrologv 1991;7: disease

27 Trudel M, D'Agati V, Constantine F. c-myc as an inducer of polycystic kidney disease in transgenic mice. Kidney Int 1991;39:665-71.

28 Sigmund $\mathrm{C}$, Gross $\mathrm{K}$. The molecular biology of the murine renin genes. Hypertension 1991;18:446-57.

29 Weiher H, Noda T, Gray DA, Sharpe AH, Jaenisch R. Transgenic mouse model of kidney disease: insertional inactivation of ubiquitously expressed gene leads to nephrotic syndrome. Cell 1990;62:425-34. 